\title{
Sobre sistema educativo y complejidad
}

\author{
Myriam Lucía Pineda González ${ }^{1}$
}

Recibido: 08 de septiembre 2011 Aceptado: 29 de noviembre 2011

Entender el concepto de sistema complejo y analizar las relaciones entre educación y sociedad, evidencia la relación entre educación, bienestar y crecimiento. La calidad de la misma implicaría desarrollar en el individuo la capacidad de responder a los desafíos de un entorno, cultural y tecnológicamente determinado, y que sea adecuada a las exigencias de un entorno cambiante.

¿Por qué han resultado tan importantes para la universidad en general y para la UNAD en particular, las enseñanzas de la Teoría de Sistemas Complejos? ¿Y en general una comprensión mayor del funcionamiento del sistema escolar y del sistema social? La respuesta resulta obvia, porque todo está relacionado, pero es importante entender la relación, lo cual redundará en desempeñar mejor nuestra función educativa.

Al igual que en otros campos, la discusión a cerca de la igualdad de oportunidades educativas, ha sido central en la historia de la sociología de la educación, en donde diversos autores muestran que una solución reformista al problema concreto de la desigualdad educativa es difícil, ya que la igualdad requeriría eliminar la estructura meritocrática, pero la reforma no se puede dar en un sistema educativo que propone socializar alumnos dentro de una sociedad estratificada en clases.

El orden político de la modernidad se sintetiza en la idea de igualdad, este es el deber ser que se encuentra en contradicción con un mundo moderno con grandes desigualdades económicas.

La teoría del conocimiento sociológico destaca el carácter político de la educación; lo cual es básico en una sociedad marcada por el aumento de las desigualdades sociales, exigencias de mano de obra adaptable a los requerimientos del capital y una reducción de los derechos sociales. En este contexto el producto del proceso educativo es una población estratificada en la que coexisten individuos ambiciosos 
y convencidos de sus méritos intelectuales por un lado, y derrotados prematuros por otra (Brunet y Morell, , 1988:164).

La visión que el funcionalismo tiene de la institución escolar parte de un doble supuesto: la neutralidad moral de la escuela y su lugar central como mecanismo de reproducción de la cultura, de la sociedad conforme a una lógica intrínsecamente meritocrática. Esta visión queda reflejada en la teoría del capital humano y en la teoría técnico-funcionalista de la modernización. Ambas teorías, también contemplan la educación como factor clave de producción o como una inversión que incrementa la capacidad de los individuos para adquirir salarios más elevados. Estas teorías que parten de un enfoque claramente evolucionista y conciben el desarrollo económico de forma teleológica, es decir, como un fin al que todas las naciones deben aspirar, sirvieron para legitimar científicamente la expansión educativa que el mundo desarrollado conoció a partir de la postguerra. (Brunet y Morell, , 1988:182).

En definitiva, la educación no conlleva un mayor rendimiento en el empleo, más bien lo que genera es una alta insatisfacción en los graduados, ya que como lo afirma Bourdieu (1978), sólo una minoría, que son quienes disponen de capital social, cultural y relacional necesario, pueden sacar suficiente provecho de sus títulos académicos.

En otras palabras, en los sistemas educativos convencemos a nuestros alumnos de que todos tienen las mismas oportunidades, pero si se olvida la relación que existe con el capital social, y la forma como se adquiere, muchos se sentirán derrotados en la búsqueda de la excelencia, si saber por qué; es allí donde adquiere importancia entender la complejidad tanto de la educación y sus contextos como del mundo del trabajo.

Muchas ideas concebidas en las ciencias físicas nos pueden ayudar a interpretar el mundo social, si son vistas integralmente. Los complejólogos hacen algo de esto, buscan un saber integrado y coherente, una visión no reduccionista de la realidad ya que el orden no puede ser impuesto, no en un sentido organizador, creador y activador de sistemas vivos, dinámicos; el orden impuesto, forzado, conduce más bien al exceso de desorden, a la muerte.

Nuestra necesidad de ser o al menos parecer «normales» puede llevarnos a negarnos a reconocer nuestras «anormalidades», nuestros impulsos «impuros», «sucios», «desordenados» nuestra concepción del mundo así que algunos por comodidad, por temor, accedemos a conformarnos con adaptar ese desorden a una clasificación de anormalidad que le otorga su lugar en nuestro mundo, eso es simplificar, mutilar lo real.

Las crisis, los desperdicios, lo irracionalizable, están ahí irremediablemente, aunque nos neguemos a verlo y queramos seguir con nuestras estructuras $\mathrm{y}$ 
seguridades. Están ahí las crisis porque estamos vivos, porque la vida para mantenerse cambia, se transforma constantemente, nunca esta quieta, el exceso de desorden la conduce a la muerte y el exceso de orden también, la vida finalmente es un milagro, en un océano de la muerte, en este sentido podríamos llegar a pensar lo que se encuentra vivo como un sistema, y nuestro universo como un sistema de sistemas.

La forma en que se concibe el mundo y la percepción que se tenga de lo que es real, lo que determina la forma en que nos relacionamos, nuestras actitudes y comportamientos, si nuestras visiones al respecto cambian, se amplían, se complejizan nuestras actitudes, nosotros cambiamos, nos transformamos, demostramos que seguimos vivos y podemos mantener la vida a nuestro alrededor. Por otra parte, el ruido, el error, también produce desorden, así como el creer tener la verdad acerca del orden, produce desorden porque el exceso de orden también produce desorden extremo, muerte.

La información siempre está en relación con la organización, la entropía en lo que concierne al sujeto humano se convierte en la falta de información de un observador sobre el sistema que considera; la entropía mide no solo el desorden o ausencia de organización en el seno de un sistema físico, sino a la vez, la reducción de las posibilidades de información de un observador sobre su observación; la entropía se convierte pues en la medida de nuestra ignorancia (Morin, 1993:324).

La vida es frágil y fuerte a la vez, no podemos esperar que sea solo una cosa firme y segura, es el amor lo que da la solidaridad, esa neguentropía superior de la que habla Morín, no el amor enfermo como nosotros, el amor que hace que veamos que lo que hacemos tienen una influencia sobre los demás y sobre todo lo que nos rodea, ese amor que nos hace ser consientes de que estamos vivos, continuamente en un paso de la muerte.

Edgar Morín escribe, de una manera que me parece encantadora que se siente en el bucle del vivir para vivir: "vivo para conocer, conozco para vivir, estoy en el circuito jugar, gozar, actuar, explorar, buscar, conocer, y este juego rotativo se finaliza por la "Búsqueda de la verdad" para el "bien de la humanidad"».

El cosmos es como el hombre sapiens/demens. El hombre sapiens transforma el alea en organización, el desorden en orden, el ruido en información, el hombre demens está atravesado por pulsiones, deseos, delirios, éxtasis, fervores, adoraciones, espasmos, ambiciones, esperanzas que tienden al infinito. El termino sapiens/demens no solo significa relación inestable, complementaria concurrente y antagonista entre la «sensatez» (regulación) y la «locura» (desajuste), significa que hay sensatez en la locura y locura en la sensatez.

A partir de una visión más compleja de la realidad es posible concebir todo objeto como un sistema, todo lo que era unidad elemental, incluido sobre todo el átomo se 
convierte en sistema. No se pueden aislar ni los objetos entre sí, ni de su ambiente, ni de su observador-conceptuador.

Este universo está dotado de generatividad, «sus encuentros» e interacciones entre sus eventos/elementos en nuestro espacio-tiempo, permiten concebir, con el necesario ingrediente del desorden, la constitución del orden, la morfogénesis organizadora de seres y existencias, los desarrollos diversificadores y complejizadores , de ahí el tetrálogo

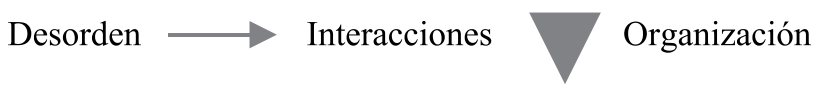

Orden

La organización de un sistema y el sistema mismo están constituidos por interrelaciones. La noción de sistema completa la noción de organización, tanto como la noción de organización completa la de sistema (Morin, 1993).

En la naturaleza no hay un principio sui generis de organización que provoque la organización u organtropia, que provoque de por si la reunión de los elementos que deben constituir el sistema. En cambio hay unas condiciones físicas de formación donde ciertos fenómenos de interacciones, toman forma de interrelaciones y devienen en organizacionales.

Toda interrelación dotada de cierta estabilidad o regularidad toma carácter organizacional y produce un sistema. Por lo tanto hay una reciprocidad circular entre estos tres términos: interrelación, organización, sistema. La idea de interrelación se refiere a los tipos y formas de unión entre elementos o individuos y entre estos y el Todo. La idea de sistema remite a la unidad compleja del Todo interrelacionado, a sus caracteres y sus propiedades fenoménicas. La idea de organización remite a la disposición de las partes dentro, en y por un Todo.

Los constreñimientos en las partes, que imponen restricciones y servidumbres, al hacerles perder o inhibir propiedades, nos permiten decir que el todo es menos que la suma de las partes.

En la sociedad la cultura permite el desarrollo de las potencialidades del espíritu humano, pero es también la sociedad la que impone coerciones y represiones a todas las actividades, desde las sexuales hasta las intelectuales.

Los sistemas no son solo uno/múltiples, son también uno/diversos. Su diversidad es necesaria para su unidad y su unidad es necesaria para su diversidad. Uno de los rasgos fundamentales de la organización es su aptitud para transformar la diversidad en unidad, sin anular la diversidad y también para crear la diversidad en y por la unidad. Un orden repetitivo que se traduce en muy poca diversidad 
genera sistemas pobres con pocas posibilidades para sobrevivir, también un sistema con extrema diversidad corre el riesgo de destruir la organización y transformarse en dispersión.

Las partes tienen una identidad propia y participan de la identidad del todo. Por muy diferentes que puedan ser, los elementos o individuos que constituyen un sistema tienen al menos una identidad común de pertenencia a la unidad global y de obediencia a sus reglas organizacionales.

La organización de un sistema es la organización de la diferencia. Establece relaciones complementarias entre las diferentes y diversas partes, así como entre las partes y el todo. La complementariedad organizacional puede instituirse de diversas formas como, por ejemplo:

- Asociaciones y combinaciones de actividades complementarias

- Uniones que instituyen un arte común

- Interacciones

- Comunicaciones informacionales

Los sistemas están sujetos a crisis. Toda crisis cualquiera que sea su origen, se traduce en una diminución de la regulación, es decir en el control de los antagonismos. Cuando más rica es la complejidad organizacional hay más tendencia hacia las crisis, pero también el sistema es más capaz de superarlas, incluso de sacar provecho de ellas para su desarrollo.

Por lo tanto la degradación, la ruina, la desintegración no provienen solamente del exterior, también provienen del interior. La muerte aleatoria del exterior se una a la muerte escondida en el interior de la organización.

La organización es el concepto crucial, el nudo que une la idea de interrelación a la idea de sistema. La organización une, transforma los elementos en un sistema, lo produce y lo mantiene, es al mismo tiempo el principio ordenador que asegura la permanencia, pero la reducción del sistema a la organización traería una pérdida de fenomenalidad y de complejidad.

Podemos concebir el nacimiento del sistema en y por las interacciones que se convierten en interrelaciones, y su existencia en las condiciones exteriores dadas.

Un sistema auto-eco-organizado a la vez que se desprende del ambiente, se distingue de él, en lo cual radica su autonomía y su individualidad. En un sistema auto-eco-organizado la individualidad está ligada a relaciones muy ricas, aunque dependientes, con el ambiente. El ambiente está dentro de él jugando un rol co- 
organizador. Solo se completa si introduce en sí mismo el ambiente ajeno sin el cual no es posible que se baste a sí mismo.

Es después de entender el concepto de sistema complejo y de analizar las relaciones entre educación y sociedad, que vemos que hay una relación directa entre educación, bienestar y crecimiento. La calidad de la misma implicaría desarrollar en el individuo la capacidad de responder a los desafíos de un entorno, cultural y tecnológicamente determinado, y que es adecuada a las exigencias de un entorno cambiante.

\section{Referencias bibliográficas}

Bourdieu, Pierre. Falta referencia.

Brunet, Ignasi y Antonio Morell. 1998. Clases, educación y trabajo. Madrid, Trotta.

Morin, Edgar. 1993. El método I. La naturaleza de la naturaleza. Madrid, Cátedra.

Morin, Edgar. 1993. El método II. La vida de la vida. Madrid, Cátedra.

Morin, Edgar. 1993. Introducción al pensamiento complejo. Madrid, Gedisa. 